\title{
Flagellin increases death receptor-mediated cell death in a RIP1-dependent
}

manner

Dora Hancz ${ }^{\dagger}$, Aniko Szabo, \#, Tamás Molnar \#, Zsofia Varga ${ }^{\#}$, Aniko Hancz ${ }^{\dagger}$, Andrea Gregus \#, Anne-Odile Hueber ", Eva Rajnavolgyi ${ }^{\#, \|}$, Gabor Koncz ${ }^{\#, \|}$

${ }^{\dagger}$ Immunology Department, University Eötvös Lorand, H-1117 Budapest, Hungary

\# Department of Immunology, Faculty of Medicine, University of Debrecen, Debrecen, Hungary

^ University Nice Sophia Antipolis, CNRS, Inserm, iBV, 06100 Nice, France

"Sapientia Hungarian University of Transylvania, Dept. of Bioengineering

Corresponding Author: Gabor Koncz, PhD;

address: Department of Immunology, Faculty of Medicine, University of Debrecen, H-4032 Debrecen, 1 Egyetem Square

Phone/Fax: +36 52417 159,

e-mail: konczgb@gmail.com 


\section{ABSTRACT}

Efficient adjuvants have the potential to trigger both innate and adaptive immune responses simultaneously. Flagellin is a unique pathogen-derived protein, which is recognized by pattern recognition receptors (PRRs) as well as by B-cell and $\mathrm{T}$ cell receptors thus providing an important link between innate and adaptive immunity. The aforementioned properties define flagellin as an optimal adjuvant. The induction of immunogenic cell death could be an additional expectation for adjuvants in the context of cancer immunotherapy due to their ability to activate dendritic cells (DC) to present tumor antigens through the engulfment of dying cells. The immunostimulatory potential of flagellin in the course of DC and lymphocyte activation is well documented, however the exact mechanism is not fully explored. Based on this limitation we sought to investigate the potential modulatory effects of flagellin on various cell death processes knowing that it plays detrimental roles in regulating the final outcome of various types of immune responses.

Here we provide evidence that the pre-treatment of Jurkat T-cells with recombinant flagellin is able to increase the degree of cell death provoked by FasL or TNF- $\alpha$, and concomitantly increases the cytotoxic potential of phytohemagglutinin activated T-lymphocytes in a TLR5 dependent way. In contrast to these flagellin-mediated effects on the death receptor-induced signaling events, the mitochondrial apoptotic pathway remained unaffected. Furthermore, the cell culture supernatant of wild type Salmonella enteritidis bacteria, but not their flagellin deficient variant, was able to enhance the Fas-induced cell death process. To define the molecular mechanisms of flagellin-mediated elevated levels of cell death we were able to detect the upregulation of RIP1-dependent signaling events. These findings demonstrate that the cooperative actions of pattern recognition and different death receptors are able to initiate the cell death process with the mobilization of RIP-dependent cell death modalities. This finding highlights the capability of flagellin to act as a potential adjuvant which is relevant for tumor immunotherapy.

Keywords: TLR, adjuvant, apoptosis, necroptosis, T cell, PAMP 


\section{INTRODUCTION}

The immunogenicity of tumors is much lower than the intensity of adaptive immune responses induced by various infections. To circumvent this limitation, the expectation would be to develop potent immune stimulatory strategies, which are able to increase the efficacy of anti-tumor immunotherapies. Efficient activation of pattern recognition receptors (PRR) is mandatory for DC maturation, migration to secondary lymphatic organs and potent antigen presentation. Furthermore, the efficient engulfment of dead cells by DCs is essential for the activation of naïve cytotoxic $\mathrm{T}$ cells to support all of these functional activities . Based on this scenario a competent adjuvant must have the potential to activate innate immunity in concert with the concomitant triggering of DC-mediated cross-presentation.

It is well established that the innate immune system can effectively be stimulated via the recognition of microbe associated molecular structures referred to as pathogen associated molecular patterns (PAMPs) which are not expressed by eukaryotic hosts. Flagellin is a subunit of bacterial flagella, which is considered as a PAMP and recognized by Toll-like receptor 5 (TLR5) to trigger cell activation and induce innate immune responses . Cytosolic flagellin can also be recognised by the apoptosis-inhibitory protein (Naip5) leading to the oligomerization of CARD domain-containing protein-4 (NLRC4/Ipaf) followed by caspase-1 activation resulting in IL-1 $\beta$ maturation and release in a TLR5-independent manner . It has previously been shown that flagellin acting as a protein type PAMP, contains MHC class-II epitopes and is also able to activate T-lymphocytes in an antigen specific manner. Thus flagellin has been identified as a unique and highly efficient activator of adaptive immune responses . In addition to these properties, flagellin acts as a T-cell dependent antigen and is able to induce robust B-cell responses to induce simultaneous activation of both arms of the adaptive immune response. . Thus, flagellin represents a unique type of protein which can be recognized by both PRRs and antigen specific receptors; emerging as a protein with adjuvant properties. The bifunctional character of flagellin also allows T-cell activation through different mechanisms that involve: 1) modification of T-cell functional activities when presented as a TCR epitope ; 2) direct stimulation of PRRs when expressed on the cell surface of T-lymphocytes ; 3) activation of antigen presenting cells by PRR triggering .

Mechanistically, apoptosis can be executed by both intrinsic and extrinsic mechanisms. Stress stimuli act preferentially via permeabilization of the mitochondrial membrane, which triggers the intrinsic activation pathway regulated predominantly by the actual balance of the 
interacting pro- and anti-apoptotic proteins belonging to the Bcl-2 family, as well by the ratio of proteins involved in the regulation of mitochondrial depolarization. In contrast to these mechanisms, the extrinsic pathways are mediated by cell death receptors, including the Fas (CD95/Apo-1/TNFSR6) receptor-ligand system. Engagement of the cell death receptors by FasL leads to the rapid recruitment of the adapter molecule FADD, while the pro-enzyme caspase-8 interacts through its death-effector domain (DED) with the homologous DED of FADD forming the death-inducing signalling complex (DISC). These events result in the activation and processing of caspase- 8 acting as an initiator caspase. Depending on the actual level of activated caspase- 8 , the executing caspases become activated directly in type-I cells or require the cleavage of Bid to trigger the mitochondrial apoptotic pathway in type-II cells. The truncated form of Bid (tBid) dominates the pro-apoptotic phase of the Bcl-2 family actions thus turning the balance of the anti- and pro-apoptotic proteins towards mitochondrial depolarization (Reviewed in ). These apoptotic pathways finally converge to the activation of effector caspases, preferentially to caspase-3, caspase-6 and caspase-7.

Death receptors can also induce apoptosis through different molecular pathways:1) aside from the classical TNF-FADD-caspase-8 complex, a RIP1-dependent cell death route can also be activated resulting in the formation of ripoptosomes associated with cell death independently of mitochondrial depolarization . 2) Depending on the availability of active caspases, RIP1mediated cell death may also lead to apoptosis or programmed necrosis i.e. necroptosis.

It is also well established that these cell death modalities may affect the activation of both innate and adaptive immunity. Dying cells in general may initiate innate immune responses by producing damage associated molecular patterns (DAMPs) referred to as inflammatory cell death. Dendritic cells (DC) have the potential to continuously engulf dead cells and are able to present the generated antigenic fragments, derived from the infected or malignant cells, to trigger naïve cytotoxic $\mathrm{T}$ cells, while cross-priming remains the only route to initiate classical CD8+T cell responses. Ongoing RIP1-mediated cell death signaling in dying cells supports the efficacy of cross priming and also increases the immunogenicity of DCs. Thus during the RIP1-dependent pathway the cell death process, also referred to as immunogenic cell death, has been shown to activate efficient cross-presentation .

The contribution of flagellin to various cell death signaling events is associated with considerable ongoing discussion, since both the anti- and the pro-apoptotic characteristics of flagellin have been described. For example, decreased apoptosis has been detected in epithelial cells or in neutrophil granulocytes upon treatment with purified flagellin or flagellated bacteria, as compared to non-flagellated variants , and death receptor-mediated 
apoptosis could also be inhibited by flagellin . In contrast to these results, flagellin was also found to be able to elicit cell death in different cell types including primary human macrophages, IEC6 intestinal epithelial cells and HeLa cells . Furthermore, the extrinsic cell death pathway could also be initiated in a TLR5 dependent manner. In the presence of Legionella pneumophilia in Jurkat cells the processing of caspase-3 and caspase-9 could be observed, but it could not be detected in the presence of a flagellin deficient variant of the bacteria .

Here, we demonstrate for the first time that flagellin has the potential to enhance the efficacy of death receptor-mediated apoptosis in a RIP dependent manner, while it has marginal effects on the intrinsic cell death process. Based on these results we suggest that the regulatory pathways identified by the current study could be harnessed for vaccination strategies by using flagellin as a potential adjuvant. 


\section{MATERIALS AND METHODS}

2.1 Cell lines: The human Jurkat T-cell line, its RIP1-deficient variants and the human WSU B-cell line were cultured in RPMI 1640 medium supplemented with 10\% FCS, 2 mM 1glutamine, $10 \mathrm{U} / \mathrm{ml}$ penicillin, $10 \mathrm{~g} / \mathrm{ml}$ streptomycin, $10 \mathrm{mM}$ HEPES and maintained at $37^{\circ} \mathrm{C}$ in a humidified atmosphere with $5 \% \mathrm{CO}_{2}$.

2.2 Antibodies and reagents: Ultrapure recombinant flagellin and neutralizing anti-TLR5 were purchased from Invitrogen. FasL and the mitochondrium dye $\mathrm{DiOC}_{6}$ were from Enzo Life Sciences. TNF and IL-2 were purchased from PeproTech, the anti-flag M2 antibody, RNase A, propidium iodide (PI), necrostatin-1 and paclitaxel from Sigma-Aldrich. The antibodies were purchased from the following companies: Biolegend (APC-labelled anti-Fas (DX2) and anti-TNFR The luminescent substrate caspase-3 was from Promega, anti-CD11c for flow cytometry analysis was from Biolegend, the CellTracker was from Lifetech, and ZVad were from Apexbio.

2.3 Flow cytometry: $10^{6}$ Jurkat cells were cell surface-stained with APC-labelled anti-Fas $\mathrm{mAb}$ (clone DX2) or anti-TNFR for $30 \mathrm{~min}$ on ice. Cells were analyzed by flow cytometer (FACS Calibur; Becton Dickinson) using the CellQuest software (Becton-Dickinson).

2.4 Production of T cell supernatants: Freshly separated PBMCs were activated with $2 \mu \mathrm{g} / \mathrm{ml}$ PHA for 6 days using $2 \mathrm{ng} / \mathrm{ml}$ IL-2 in cell culture medium changed every 48 hours. At a density of $4 \times 10^{6}$ cells $/ \mathrm{ml}$ the cells were harvested on day 6 , and the T-cell blasts were stimulated with $100 \mu \mathrm{g} / \mathrm{ml}$ PHA for $5 \mathrm{~min}$. Following cell activation and repeated washings, the cell cultures were replenished with fresh medium. After 2 hours the supernatants were collected and the target cells were triggered with the supernatants of PHA activated T-cells for 24 hours. To get the same cell death intensity, in case of wild type cells T-sup was diluted (1:2), while remained undiluted when used for RIP1 deficient cells. The degree of cell death was determined by flow cytometry by detecting the subG1 population.

2.5 Bacterial supernatants: The culture supernatants derived from wild type and/or flagellin deficient $\mathrm{FliC}^{-/-}$Salmonela enteritidis were centrifuged at $15,000 \times g$ for $30 \mathrm{~min}$. The supernatant was dialyzed against $10 \mathrm{mM}$ Tris- $\mathrm{HCl}$ buffer and the dialyzed sample was concentrated with a 10k Amicon Ultra device. 
2.6 Cytotoxicity assays: $5 \times 10^{5}$ cells in a volume of $0,5 \mathrm{ml}$ were pre-treated with $100 \mathrm{ng} / \mathrm{ml}$ recombinant flagellin for $60 \mathrm{~min}$. The sensitivity of the target cells to cell death was examined by incubating the cells with $20 \mathrm{ng} / \mathrm{ml}$ recombinant Flag-tagged FasL, $10 \mathrm{ng} / \mathrm{ml}$ recombinant TNF or with $500 \mathrm{ng} / \mathrm{ml}$ paclitaxel. Alternatively, cells were subjected to $354 \mathrm{~nm} \mathrm{UV}$ irradiation for $10 \mathrm{~min}$. The degree of cell death was analyzed by measuring caspase-3 activity detecting mitochondrial membrane depolarization, Annexin V staining, as well as by measuring the subG1 peak indicating apoptotic cells.

SubG1 measurement: Cells were fixed on ice-cold $70 \%$ ethanol, washed with $38 \mathrm{mM}$ citrate buffer ( $\mathrm{pH} 7.4$ ) and were incubated in $38 \mathrm{mM}$ citrate buffer supplemented with $50 \mathrm{mg} / \mathrm{ml}$ PI and $5 \mathrm{mg} / \mathrm{ml}$ RNase A for $15 \mathrm{~min}$. The treated cells were analyzed by a FACS Calibur flow cytometer (BD Biosciences) followed by measuring the proportion of subG1 particles.

Annexin V detection kit (Biovison) was used according to manufacture's protocol. Caspase-3 activity was measured after the pretreatment of the cells with $100 \mathrm{ng} / \mathrm{ml}$ recombinant flagellin for 1 hour followed by incubation with $60 \mathrm{ng} / \mathrm{ml} \mathrm{FasL}$ for 24 hours at $37^{\circ} \mathrm{C}$. We used the cellpermeable fluorogenic substrate Caspase-Glo® 3/7 Promega Assay for monitoring caspase-3 activity in the intact cells, according to the manufacturer's recommendations. Mitochondrial depolarization was measured following pre-incubation with $100 \mathrm{ng} / \mathrm{ml}$ recombinant flagellin for 1 hour and stimulation with $20 \mathrm{ng} / \mathrm{ml} \mathrm{FasL}$ for 4 hours at $37^{\circ} \mathrm{C}$. Thereafter, the cells were incubated with $20 \mathrm{nM} \mathrm{DiOC} 6$ for $30 \mathrm{~min}$ at $37^{\circ} \mathrm{C}$. After three washing steps in PBS, mitochondrial depolarization was detected by a FACS Calibur flow cytometer.

2.7 Co-cultures: The FasL-overexpressing WSU B-cell line used as effector cells were resuspended in $5 \mathrm{mM}$ CellTracker. After $30 \mathrm{~min}$ incubation at $37^{\circ} \mathrm{C}$ the cells were centrifuged, the CellTracker solution was replaced with fresh medium and cells were incubated for another $30 \mathrm{~min}$ at $37^{\circ} \mathrm{C}$. After repeated washing steps the cells were added to the target cells at a ratio of $1: 1$ or $5: 1$. Effector and the target cells were co-cultured for 24 hours and the percentage of dead cells was determined in the CellTracker negative population by flow cytometry.

2.8 Detection of necroptotic cells: Jurkat cells were pre-treated with $10 \mu \mathrm{M} Z$-Vad and $40 \mu \mathrm{M}$ necrosatin-1 for 1 hour. As a next step the cells were incubated with flagellin for another hour and were co-incubated with the effector cells for 24 hours. Following the CellTracker staining of the FasL-overexpressing WSU B-cells the ratio of the effector and the target cells were 
adjusted to 5:1. Before the flow cytometry analysis the cells were stained with $10 \mu \mathrm{g} / \mathrm{ml}$ PI. Total cell death was quantified based on the loss of membrane integrity and the uptake of PI.

2.9 Statistical analysis: Mean values plus standard deviation of at least three independent experiments are shown. Statistically significant differences were determined by using oneway ANOVA test. *: $p<0.05 ; * *: p<0.01$ and $* * *: p<0.001$. 


\section{RESULTS}

\subsection{Recombinant flagellin upregulates Fas-induced apoptosis}

Flagellin has been identified as a PAMP, which can be presented for T-cells. Apart from providing proper activation signals to the TCR, flagellin is also able to initiate signaling cascades in $\mathrm{T}$ cells mediated by PRR activation. In this study we aimed to identify and characterize the functional activities of flagellin in the course of various cell death processes, with special emphasis on its role in the extrinsic DR-mediated cell death process. . As a model system, we designed in vitro experiments using Jurkat acute leukemia T-cells expressing TLR5 . The expression of TLR5 on the surface of Jurkat T-cells could be detected at both RNA and protein levels and functional assays confirmed the operation of active

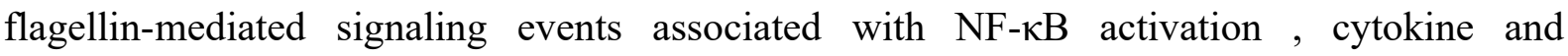
chemokine production .

To analyze the effects of flagellin on Fas-induced apoptosis, we first used the FasL sensitive SVT35 Jurkat T-cells pre-treated with $100 \mathrm{ng} / \mathrm{ml}$ recombinant flagellin. In this experimental setup cell death was induced by flag-tagged recombinant FasL crosslinked with an anti-flag antibody, or with FasL-expressing WSU B-cells. The degree of cell death was quantified after 24 hours by monitoring the extent of apoptosis given in the percentage of cells containing sub-diploid DNA (subG1) (supplementary Figure 1A). T cell death intensity was also determined with annexin V staining (supplementary Figure 1B). These results indicated that the treatment of Jurkat T-cells with flagellin only had no modifying effect on apoptosis, but the pre-treatment of Jurkat cells with flagellin significantly increased the degree of Fasinduced apoptosis (Figure 1A, B). Importantly, the elevated level of apoptosis was independent on the mode of Fas receptor-mediated stimulation, since flagellin could enhance the cell death process induced by soluble recombinant as well as cell surface expressed FasL. In contrast, the WSU cells not expressing FasL were unable to induce cell death (data not shown). In a further step the kinetics of flagellin-mediated Fas-induced cellular killing was monitored. Flagellin were able to increase the Fas-induced cell death as early as 8 hours, however significant differences was detected only upon 24 hours (Figure 1C). These results clearly demonstrate that the pre-treatment of Jurkat cells with recombinant flagellin is sufficient to upregulate the Fas-induced cell death process.

\subsection{The culture supernatants of flagellin secreting bacteria can enhance the Fas-induced cell} death process 
The observation that recombinant flagellin is able to promote the Fas-induced cell death process prompted us to test the effects of flagellin, released by live bacteria. In this context we addressed the question of whether the supernatants derived from the Salmonella enteritidis strain and its flagellin deficient counterpart could modulate the Fas-induced cell death process. In this experimental setting Jurkat cells were pre-treated with filtered cell culture supernatants containing $>10 \mathrm{kDa}$ molecules released from bacteria, which expressed or lacked flagellin. In this experimental setting the flagellin free supernatants had no effect on the Fasmediated cell death process, while the supernatants of wild type flagellin expressing bacteria, similarly to the recombinant flagellin, were able to increase the intensity of Fas-induced apoptosis (Figure 2). Considering that the supernatants of flagellin deficient bacteria did not modify the outcome of the Fas-induced cell death process, these experiments point to the contribution of flagellin to the regulation of Fas-mediated apoptosis. Overall, these results confirm that in Jurkat T-cells flagellin mediates a supportive effect on the Fas-induced cell death process.

\subsection{Recombinant flagellin has the potential to increase the level of death receptor-induced} apoptosis in a TLR5 dependent way.

Confirming that flagellin has the potential to enhance the activity of Fas-induced cell death, we sought to analyze the impact of flagellin on other types of death receptor-mediated signaling events. Taken that the SVT35 Jurkat cells are sensitive to TNF-induced apoptosis, we aimed to determine the contribution of flagellin to the TNF-induced signaling pathways. To this end, the cells were first pre-treated with $100 \mathrm{ng} / \mathrm{ml}$ recombinant flagellin for an hour followed by the stimulation of the cells with $10 \mathrm{ng} / \mathrm{ml}$ recombinant TNF for 24 hours. Similar to the results obtained during the Fas-generated cell death process, flagellin could significantly enhance TNF-induced apoptosis (Figure 3A).

Killing of target cells by cytotoxic T-lymphocytes is induced by direct cell-to-cell contact and/or by secreted microvesicles. FasL, TRAIL, TNF and other soluble factors may also contribute to the cytotoxic activities of these T-cell supernatants. Considering the possible involvement of other contributing factors and mechanisms exerted on the various cell death processes, we also measured the killing potential of the T-cell supernatants (T-sup) both in the presence and absence of flagellin. In accordance with our previous results we found that the supernatants derived from PHA-activated primary T-cells exhibited cytotoxic activity, which culminated in the killing of Jurkat cells . These experiments revealed that flagellin pretreatment was able to enhance the degree of the activated T-lymphocytes derived supernatant- 
induced cell death, similarly to the results obtained from recombinant FasL or TNF (Figure 3B). These results confirmed the significant contribution of flagellin to the upregulation of the cell death process induced by cytotoxic T-cells upon soluble factor-mediated stimuli.

To test whether flagellin-mediated enhancement of death receptor-induced cell death was a TLR5 dependent process, we pretreated the cells with a neutralizing anti-TLR5 antibody for 1 hour. Antagonistic TLR5 antibody completely blocked the flagellin-induced enhancement of death receptor triggered apoptosis (Figure 3C) suggesting that flaggelin exerts its effect on cell death by the means of TLR5 signaling.

\subsection{Flagellin has no modulatory effect on the cell death process in neutrophil granulocytes}

As shown before, flagellin is able to inhibit apoptosis in neutrophil granulocytes when an agonistic anti-Fas antibody was used. To get a better insight into the cell death process initiated in neutrophil granulocytes, fresh neutrophil granulocytes were treated with flagellin in the presence or absence of recombinant FasL. Subsequently, the intensity of cell death was determined by capturing the subG1 cell population 8 hours after FasL-mediated stimulation. As expected, granulocytes readily undergo spontaneous cell death at as early as 8 hours, and this process could be further increased by FasL-mediated stimulation. However, flagellin pretreatment was unable to elevate the cell death process both in non-stimulated or FasL activated cells at any of the investigated time points suggesting that the flagellin-mediated enhancement of death receptor-induced cell death is strictly cell type dependent (Figure 4).

\subsection{Flagellin pre-treatment upregulates caspase-3 activation, but it has no effect on mitochondrial depolarization}

In the course of cell death receptor mediated signaling the possible molecular targets of flagellin have not yet been identified. To get insight into the multi-stage processes of cell death events we next sought to identify the checkpoints of the cell death events in the presence of flagellin. First, we measured the expression level of Fas and TNF receptors on the cell surface followed by flagellin treatment. The histograms presented in Figure 5A and B demonstrate that the level of TNF receptor expression remains unaffected for 24 hours, but Fas expression was increased upon flagellin-induced stimulation. Thus the supportive effect of flagellin during the cell death process can partially attributed to the up-regulated expression of the Fas receptor, but it cannot explain the flagellin-mediated upregulation of TNF-induced cell death. 
Death receptor-mediated stimulation can also induce caspase-3 activation with or without mitochondrial depolarization depending on the action of type I or II cells. Flagellin pretreatment did not change the intensity of mitochondrial membrane depolarization caused by FasL stimulation (Figure 5C). In contrast to these observations, co-stimulation with FasL and flagellin provoked enhanced caspases-3 activity at both 6 and 24 hours after stimulation (Figure 5D). This is consistent with the increased apoptotic cell death detected in the subG1 cell population. Identification of these molecular actors of the Fas/TNF signaling pathway led us to conclude that flagellin has no direct impact on mitochondrial depolarization, but it is involved in downstream processes including effector caspase activities, which may contribute to the flagellin-mediated enhancement of cell death.

\subsection{Flagellin is inefficient to modulate stress induced apoptosis}

Apoptosis can be mediated by both intrinsic and extrinsic processes. Taken that flagellin can modify the activity of effector caspases without affecting mitochondrial membrane depolarization, we sought to study the potential role of flagellin in stress-induced apoptosis. To this end we incubated the SVT35 Jurkat cells with flagellin for 1 hour followed by UV irradiation, or treatment with the chemotherapeutic agent paclitaxel to provoke mitochondrial apoptosis. In contrast to the results obtained with death receptor-induced apoptosis, flagellin pre-treatment was unable to enhance stress-induced apoptosis. This suggests that even though flagellin has the potential to regulate death receptor-mediated apoptosis, it does not affect mitochondrial depolarization (Figure 6).

\subsection{Flagellin enhances the cell death process in a RIP1-dependent manner}

As outlined in the previous sections, flagellin is able to increase death receptor-mediated apoptosis, but has no effect on mitochondrial membrane depolarization or on the stressinduced pathway. Based on this data, we investigated the possible action of a putative death receptor-dependent but mitochondria independent process, which might be responsible for the facilitation of cell death induction. Considering that the RIP1-dependent pathway has been identified upon death receptor stimulation and can induce caspase-9 independent apoptosis , we sought to investigate whether RIP1 could be essential for the flagellin-induced enhancement of the Fas-mediated cell death process. To approach this scenario, SVT35 Jurkat cells and their RIP1-negative sub-clones were pre-treated with flagellin and subsequently stimulated with FasL, TNF, or T-sup. RIP1 deficiency of the sub-clones was confirmed by western blotting, and both the wild type and its RIP1-negative counterparts were sensitive to 
FasL-induced cell death. Nevertheless, flagellin pre-treatment resulted in significantly more intense cell death in the wild type cells compared to the RIP1 deficient cells upon FasL stimulation (Figure 7A). To further confirm the impact of flagellin on other types of death receptor-mediated signaling events, after flagellin pre-treatment, we activated the cells with TNF or T-sup. In accordance with our published results , T-sup could induce RIP1 dependent cell death. These results showed that, in contrast to the wild type cells, flagellin did not increase the intensity of T-sup- and TNF-induced cell death in the RIP1 deficient cell lines (Figure 7 B, C). These results demonstrate that RIP1-mediated signals are responsible at least partially for flagellin-mediated upregulation of FasL, TNF and Tsup -induced apoptosis.

DR-mediated stimulation of cells may also result in other types of RIP1-regulated cell death processes such as programmed necrosis or necroptosis. Necroptosis utilizes a unique signaling pathway, which aside from RIP1, also requires the involvement of RIP3 and MLKL . Upon stimulation of DRs, necroptosis requires inhibited caspase activities or the lack of the caspase-8-activating adaptor FADD , demonstrating the crucial role of the apoptotic platform in the regulation of necroptosis. To determine whether flagellin affects DR-stimulated necroptosis or its effect is restricted exclusively to DR-mediated apoptosis, we treated the SVT35 Jurkat cells with flagellin and with FasL simultaneously in the presence of the pancaspase inhibitor Z-Vad. We found that in the presence of Z-Vad strong stimulation was essential to provoke cell death. This indicates that necroptosis could only be induced by the FasL-expressing WSU B-cells used at elevated (5:1) effector/target cell ratios. Strikingly, flagellin pre-treatment of Jurkat cells was able to increase Fas-induced necroptosis to an extent similar to that observed in apoptotic conditions.

Necroptosis can be specifically inhibited by necrostatins (Nec1) or by neurosulfonamide NSA . Accordingly, in the presence of Z-Vad, the cell death process could be completely blocked by necrostatins confirming that the observed cell death processes can be validated as necroptosis. These results altogether demonstrate that flagellin pre-treatment supports both the RIP1 dependent apoptotic and necroptotic pathways. 


\section{DISCUSSION}

Activation of naïve cytotoxic $\mathrm{T}$ cells requires the engulfment of dying cells by DCs and the cross-presentation of cellular antigens. Optimized adjuvants, relevant to intracellular pathogens or tumor antigens, are not only able to activate innate immune responses, but they also preferentially induce immunogenic cell death. Agonists, which are able to activate TLRs, have been tested to boost immune responses to enforce increased anti-tumor activities. As an example, the stimulation of TLR3 or TLR4 are well known inducers of DC maturation and concomitantly induce cell death to facilitate antigen cross-presentation by DC . Flagellin is considered as an unique pathogen-derived protein, which is recognized by innate immune cells and also by various adaptive immune receptors simultaneously, thus providing an important link between the two arms of the immune system. The effects of flagellin on innate immune cells, and its ability to activate T-cells directly identifies flagellin as an adjuvant acting against infectious diseases and/or supporting the outcome of anti-cancer immunotherapies. Several approaches and various targeting strategies have already utilized flagellin operating as an adjuvant in cancer immunotherapy. Co-administration of flagellin with tumor antigens has also been tested and revealed its capacity to facilitate the induction of anti-tumor immunity .

In this study we have undertaken a detailed characterization of flagellin-mediated effects exerted on various cell death pathways. We demonstrated that the pre-treatment of Jurkat $\mathrm{T}$ cells with recombinant flagellin was able to increase the level of Fas-mediated apoptosis significantly. We also provided evidence that this type of cell death was independent of the mode of death receptor triggering, since the signals induced by both recombinant and cell surface expressed FasL were equally effective. Importantly, in the presence of flagellin the TNF- killing mechanisms could also be enhanced.

It has previously been reported that the cytotoxic function of T-cells acts as a Fas-dependent mechanism in concert with other death receptors. Soluble FasL, TNF and TRAIL have also been observed in the culture supernatants of activated T-lymphocytes suggesting that, aside from direct cell-to-cell contact-induced killing mechanisms, secreted vesicles are also able to transfer cytotoxic signals to various target cells .

In the current in vitro model system we sought to investigate the impact of soluble factors, such as culture supernatants derived from PHA pre-stimulated T-cells. The experimental results provided evidence that aside from the death ligand-induced cell death process, T-supmediated apoptosis can also be sensitized by flagellin. Upregulation of activation-induced cell death (AICD) has been evaluated as an immune evasion strategy, which decreases the number 
of antigen-specific $\mathrm{T}$ cells. At the same time, this process can also contribute to the maintenance of immune tolerance, especially in the vicinity of mucosal surfaces where significant amounts of flagellin is constantly available. The modulatory effects of flagellin via the down-regulation of the lifespan of activated T-cells points out the requirement of further studies related to the in vivo application of flagellin as an adjuvant.

It is reasonable to assume that bacterial supernatants may contain a wide range of biologically active components, including flagellin monomers. To determine the significance of flagellin mediated effects, the characteristics of flagellin deficient and wild type Salmonella enteritidis bacteria were compared based on their ability to induce apoptosis. In this experimental setting, the supernatants derived from flagellin expressing bacterium strains were able to increase the FasL-induced cell death process, while the flagellin deficient supernatant was ineffective, confirming the apoptosis enhancing potential of flagellated bacteria. This result also highlights the unique role of flagellin present in bacterial supernatants and the ability to modulate the Fas-mediated cell death process.

Our results demonstrate that although flagellin has an impact on the outcome of Fas-induced cell death and on the activation of downstream effector caspases, the intensity of mitochondrial depolarization remained unaffected.

Following TNF or FasL stimulation, RIP1-dependent apoptosis and also necroptosis are induced. Depending on the posttranslational modifications, the proteolytic inactivation of RIP1 and RIP3, as well as the poly-ubiquitinated status of RIP1, in line with the composition of the organized molecular complexes, RIP1 is able to modulate the final outcome of cell death mediated signaling events . RIP1 signaling in dying cells has been found to facilitate cross-presentation in cytotoxic T cells, . Our results also demonstrate that in the absence of RIP1 flagellin is unable to enhance the death receptor and the T-sup-induced apoptosis processes. It indicates that flagellin can upregulate the RIP1-mediated cell death process. Since caspase activation was not inhibited in these settings, RIP-mediated apoptosis could be induced.

However, in the presence of the caspase inhibitor Z-Vad intense FasL triggering can induce RIP-dependent necroptosis in Jurkat cells. Similarly to Fas-induced apoptosis, RIP-1 dependent necrosis was also enhanced by flagellin pre-treatment.

The immunological nature of the various cell death processes can either be tolerogenic, inflammatory or immunogenic. Thus, the various cell death processes have the potential to fundamentally impact the development of degenerative disorders, autoimmune processes, inflammatory diseases and tumors. The results obtained in this study indicate that flagellin not 
only activates DCs by acting as a PAMP, but at the same time may also direct various cell death pathways towards the RIP-dependent cell death pathway, which may result in enhanced DC-mediated cross-presentation. This unique capability of flagellin designates it as a potent adjuvant, which can be readily harnessed for different therapeutic settings, preferentially in tumor immunotherapies.

\section{CONFLICT OF INTEREST}

The authors declare no conflict of interest

\section{ACKNOWLEDGEMENT:}

We thank Zsuzsanna Debreceni for excellent technical assistance. This work was supported by OTKA (114423) and by the Romanian Ministry of Education, Executive Agency For Higher Education, Research, Development and Innovation Funding, PNCDI II. (project no. 119/2014) 


\section{FIGURE LEGENDS}

Figure 1. Flagellin pre-treatment enhances the activity of Fas-induced cell death

Cells of the SVT35 Jurkat T-cell line were pre-treated with $100 \mathrm{ng} / \mathrm{ml}$ recombinant flagellin for 1 hour followed by (A) the activation of cells with flag-tagged recombinant FasL (20 ng/ ml) crosslinked with the anti-flag (M2) antibody, or by (B) co-culturing with the human Bcell line WSU expressing FasL at a ratio of 1:1. After 24 hours the extent of cell death was determined by measuring the subG1 peak. Figure A and B show the mean plus standard deviation (SD) of at least four independent experiments. (C) Jurkat T-cells were pre-treated with $100 \mathrm{ng} / \mathrm{ml}$ flagellin followed by the activation with $20 \mathrm{ng} / \mathrm{ml}$ recombinant FasL in combination with the M2 anti-flag antibody. After the indicated period of time the level of cell death was determined by measuring the subG1 peak. A representative image of three independent experiments is shown.

Figure 2. Flagellin expressing, but not the flagellin deficient, bacterial supernatants are able to increase the degree of Fas-induced cell death

The supernatant of Salmonella enteritidis bacterial cultures was dialyzed and the low molecular weight fraction $(<3 \mathrm{kD})$ was removed by ultrafiltration. Jurkat T-cells were treated with the filtered supernatants of wt (FliC) or flagellin deficient bacteria $\left(\mathrm{FliC}^{-/-}\right)$for 1 hour. The pre-treated cells were stimulated with $20 \mathrm{ng} / \mathrm{ml}$ recombinant FasL in combination with the M2 anti-flag antibody. After 24 hours the degree of cell death was determined by measuring the subG1 peak. Figure shows the mean plus standard deviation (SD) of five independent experiments.

Figure 3. Flagellin pre-treatment enhances the death receptor-induced cell death process (A) Jurkat T-cells were pre-treated with $100 \mathrm{ng} / \mathrm{ml}$ flagellin for 1 hour followed by activation with $10 \mathrm{ng} / \mathrm{ml}$ recombinant TNF. After 24 hours the level of cell death was determined by measuring the subG1 peak. (B) Following the pre-incubation of the Jurkat cells with 100 $\mathrm{ng} / \mathrm{ml}$ flagellin, the cells were treated with the supernatants of PHA-activated 6 days $\mathrm{T}$ cell blasts (T-sup). After 24 hours the level of cell death was determined by measuring the subG1 peak. (C) Jurkat T-cells were pre-treated with $100 \mathrm{ng} / \mathrm{ml}$ flagellin for 1 hour in the presence or absence of neutralizing anti-TLR5. Cells were activated with flag-tagged recombinant FasL $(20 \mathrm{ng} / \mathrm{ml})$ crosslinked with the anti-flag (M2) antibody, $10 \mathrm{ng} / \mathrm{ml}$ recombinant TNF or with 
the supernatants of PHA-activated 6 days T cell blasts (T-sup). After 24 hours the intensity of cell death was determined by measuring the subG1 peak. Figure (A-C) show the mean plus standard deviation (SD) of at least five independent experiments.

Figure 4. Flagellin pretreatment has no effect on the spontaneous or the Fas-induced cell death process in neutrophil granulocytes

Freshly isolated neutrophil granulocytes were treated with $100 \mathrm{ng} / \mathrm{ml}$ recombinant flagellin. Alternatively, the cells treated with flagellin for 1 hour were also activated by $20 \mathrm{ng} / \mathrm{ml}$ recombinant FasL for 8 hours and the degree of cell death was determined by measuring the subG1 peak. The figure shows the mean plus SD of three independent experiments.

\section{Figure 5. Flagellin pre-treatment upregulates caspase-3 activation}

Jurkat cells were pretreated with $100 \mathrm{ng} / \mathrm{ml}$ recombinant flagellin for 24 hours. (A) Fas and (B) TNF receptor expression levels were detected by fluorescently labelled anti-Fas or antiTNFR antibody. A representative image of three independent experiments is documented. (CD) Jurkat cells were pre-treated with $100 \mathrm{ng} / \mathrm{ml}$ flagellin for 1 hour followed by activation with $20 \mathrm{ng} / \mathrm{ml}$ recombinant FasL together with the anti-flag M2 antibody. (C) 4 hours after the addition of FasL mitochondrial depolarization was determined by using the $\mathrm{DIOC}_{6}$ dye. (D) 24 hours after the addition of FasL to the Jurkat cells, caspase-3 activity was determined by measuring luminescent intensity.

Figure 6. Flagellin pre-treatment has no effect on intrinsic apoptosis

Cells of the Jurkat cell line were pre-treated with $100 \mathrm{ng} / \mathrm{ml}$ flagellin for 1 hour and stimulated by (A) $354 \mathrm{~nm} \mathrm{UV} \mathrm{irradiation} \mathrm{for} 10$ minutes or (B) paclitaxel (500 ng/ml) treatment. After 24 hours the degree of cell death was determined by measuring the subG1 peak. Figures show the mean plus SD of three independent experiments.

Figure 7. Flagellin pre-treatment increases the cell death process in a RIP1-dependent manner

(A-C) RIP1 deficient SVT35 Jurkat cells and their wild type counterpart were pre-treated with $100 \mathrm{ng} / \mathrm{ml}$ flagellin for 1 hour followed by activation (A) with $20 \mathrm{ng} / \mathrm{ml} \mathrm{FasL} \mathrm{crosslinked} \mathrm{with}$ the anti-flag (M2) antibody, (B) with $10 \mathrm{ng} / \mathrm{ml}$ recombinant TNF, or (C) with the supernatants of PHA-activated T cells (T-sup). In case of wild type cells T-sup was diluted (1:2), while remained undiluted for the RIP1 deficient cells. After 24 hours the degree of cell death was 
determined by measuring the subG1 peak. Figures show the mean plus SD of five independent experiments and significance was determined by using the two-way ANOVA test. (D) Cells of the Jurkat cell line were incubated in the presence or absence of $10 \mu \mathrm{M} \mathrm{Z}$ Vad and $40 \mu \mathrm{M}$ necrosatin-1 for 1 hour. After 1 hour pre-treatment with flagellin the FasLoverexpressing WSU B-cell line was added to the Jurkat cells at a 5:1 ratio. The degree of total cell death was quantified based on the uptake of PI. Figure shows the mean plus SD of four independent experiments and significance was determined by using paired t-test.

Supplementary Figure1.

(A) Cells of the SVT35 Jurkat T-cell line were pre-treated with $100 \mathrm{ng} / \mathrm{ml}$ recombinant flagellin for 1 hour followed by the activation of cells with flag-tagged recombinant FasL (20 $\mathrm{ng} / \mathrm{ml}$ ) crosslinked with the anti-flag (M2) antibody. After 24 hours the extent of cell death was determined by measuring the subG1 peak. A representative image of five independent experiments is documented.

(B) Jurkat $\mathrm{T}$-cells were pre-treated with $100 \mathrm{ng} / \mathrm{ml}$ flagellin for 1 hour followed by activation with $10 \mathrm{ng} / \mathrm{ml}$ recombinant FasL in the presence of anti-flag (M2) antibody. In 8 hours the level of cell death was determined by Annexin $\mathrm{V}$ and 7AAD staining. A representative image of three independent experiments is documented.

\section{References:}

[1] N. Yatim, S. Cullen, M.L. Albert, Dying cells actively regulate adaptive immune responses, Nature reviews. Immunology 17(4) (2017) 262-275.

[2] A.S. Neish, TLRS in the gut. II. Flagellin-induced inflammation and antiapoptosis, American journal of physiology. Gastrointestinal and liver physiology 292(2) (2007) G462-6. [3] L. Franchi, A. Amer, M. Body-Malapel, T.D. Kanneganti, N. Ozoren, R. Jagirdar, N. Inohara, P. Vandenabeele, J. Bertin, A. Coyle, E.P. Grant, G. Nunez, Cytosolic flagellin requires Ipaf for activation of caspase-1 and interleukin 1beta in salmonella-infected macrophages, Nature immunology 7(6) (2006) 576-82.

[4] K.L. Lightfield, J. Persson, S.W. Brubaker, C.E. Witte, J. von Moltke, E.A. Dunipace, T. Henry, Y.H. Sun, D. Cado, W.F. Dietrich, D.M. Monack, R.M. Tsolis, R.E. Vance, Critical function for Naip5 in inflammasome activation by a conserved carboxy-terminal domain of flagellin, Nature immunology 9(10) (2008) 1171-8. 
[5] S.E. Letran, S.J. Lee, S.M. Atif, S. Uematsu, S. Akira, S.J. McSorley, TLR5 functions as an endocytic receptor to enhance flagellin-specific adaptive immunity, European journal of immunology 41(1) (2011) 29-38.

[6] B.T. Cookson, M.J. Bevan, Identification of a natural T cell epitope presented by Salmonella-infected macrophages and recognized by $\mathrm{T}$ cells from orally immunized mice, Journal of immunology (Baltimore, Md. : 1950) 158(9) (1997) 4310-9.

[7] A.F. Cunningham, F. Gaspal, K. Serre, E. Mohr, I.R. Henderson, A. Scott-Tucker, S.M. Kenny, M. Khan, K.M. Toellner, P.J. Lane, I.C. MacLennan, Salmonella induces a switched antibody response without germinal centers that impedes the extracellular spread of infection, Journal of immunology (Baltimore, Md. : 1950) 178(10) (2007) 6200-7.

[8] M.J. Lodes, Y. Cong, C.O. Elson, R. Mohamath, C.J. Landers, S.R. Targan, M. Fort, R.M. Hershberg, Bacterial flagellin is a dominant antigen in Crohn disease, The Journal of clinical investigation 113(9) (2004) 1296-306.

[9] J.T. Bates, A.H. Graff, J.P. Phipps, J.M. Grayson, S.B. Mizel, Enhanced antigen processing of flagellin fusion proteins promotes the antigen-specific CD8 $+\mathrm{T}$ cell response independently of TLR5 and MyD88, Journal of immunology (Baltimore, Md. : 1950) 186(11) (2011) 6255-62.

[10] G. Caron, D. Duluc, I. Fremaux, P. Jeannin, C. David, H. Gascan, Y. Delneste, Direct stimulation of human T cells via TLR5 and TLR7/8: flagellin and R-848 up-regulate proliferation and IFN-gamma production by memory CD4+ T cells, Journal of immunology (Baltimore, Md. : 1950) 175(3) (2005) 1551-7.

[11] L. Galluzzi, J.M. Bravo-San Pedro, I. Vitale, S.A. Aaronson, J.M. Abrams, D. Adam, E.S. Alnemri, L. Altucci, D. Andrews, M. Annicchiarico-Petruzzelli, E.H. Baehrecke, N.G. Bazan, M.J. Bertrand, K. Bianchi, M.V. Blagosklonny, K. Blomgren, C. Borner, D.E. Bredesen, C. Brenner, M. Campanella, E. Candi, F. Cecconi, F.K. Chan, N.S. Chandel, E.H. Cheng, J.E. Chipuk, J.A. Cidlowski, A. Ciechanover, T.M. Dawson, V.L. Dawson, V. De Laurenzi, R. De Maria, K.M. Debatin, N. Di Daniele, V.M. Dixit, B.D. Dynlacht, W.S. ElDeiry, G.M. Fimia, R.A. Flavell, S. Fulda, C. Garrido, M.L. Gougeon, D.R. Green, H. Gronemeyer, G. Hajnoczky, J.M. Hardwick, M.O. Hengartner, H. Ichijo, B. Joseph, P.J. Jost, T. Kaufmann, O. Kepp, D.J. Klionsky, R.A. Knight, S. Kumar, J.J. Lemasters, B. Levine, A. Linkermann, S.A. Lipton, R.A. Lockshin, C. Lopez-Otin, E. Lugli, F. Madeo, W. Malorni, J.C. Marine, S.J. Martin, J.C. Martinou, J.P. Medema, P. Meier, S. Melino, N. Mizushima, U. Moll, C. Munoz-Pinedo, G. Nunez, A. Oberst, T. Panaretakis, J.M. Penninger, M.E. Peter, M. Piacentini, P. Pinton, J.H. Prehn, H. Puthalakath, G.A. Rabinovich, K.S. Ravichandran, R. Rizzuto, C.M. Rodrigues, D.C. Rubinsztein, T. Rudel, Y. Shi, H.U. Simon, B.R. Stockwell, G. Szabadkai, S.W. Tait, H.L. Tang, N. Tavernarakis, Y. Tsujimoto, T. Vanden Berghe, P. Vandenabeele, A. Villunger, E.F. Wagner, H. Walczak, E. White, W.G. Wood, J. Yuan, Z. Zakeri, B. Zhivotovsky, G. Melino, G. Kroemer, Essential versus accessory aspects of cell death: recommendations of the NCCD 2015, Cell death and differentiation 22(1) (2015) 5873.

[12] L. Wang, F. Du, X. Wang, TNF-alpha induces two distinct caspase-8 activation pathways, Cell 133(4) (2008) 693-703.

[13] S.L. Petersen, L. Wang, A. Yalcin-Chin, L. Li, M. Peyton, J. Minna, P. Harran, X. Wang, Autocrine TNFalpha signaling renders human cancer cells susceptible to Smac-mimeticinduced apoptosis, Cancer cell 12(5) (2007) 445-56.

[14] N. Yatim, H. Jusforgues-Saklani, S. Orozco, O. Schulz, R. Barreira da Silva, C. Reis e Sousa, D.R. Green, A. Oberst, M.L. Albert, RIPK1 and NF-kappaB signaling in dying cells determines cross-priming of CD8(+) T cells, Science (New York, N.Y.) 350(6258) (2015) 328-34. 
[15] H. Zeng, H. Wu, V. Sloane, R. Jones, Y. Yu, P. Lin, A.T. Gewirtz, A.S. Neish, Flagellin/ TLR5 responses in epithelia reveal intertwined activation of inflammatory and apoptotic pathways, American journal of physiology. Gastrointestinal and liver physiology 290(1) (2006) G96-G108.

[16] M. Vijay-Kumar, H. Wu, R. Jones, G. Grant, B. Babbin, T.P. King, D. Kelly, A.T. Gewirtz, A.S. Neish, Flagellin suppresses epithelial apoptosis and limits disease during enteric infection, The American journal of pathology 169(5) (2006) 1686-700.

[17] G.V. Salamone, Y. Petracca, J.I. Fuxman Bass, M. Rumbo, K.A. Nahmod, M.L. Gabelloni, M.E. Vermeulen, M.J. Matteo, J.R. Geffner, A.S. Trevani, Flagellin delays spontaneous human neutrophil apoptosis, Laboratory investigation; a journal of technical methods and pathology 90(7) (2010) 1049-59.

[18] L.G. Burdelya, C.M. Brackett, B. Kojouharov, Gitlin, II, K.I. Leonova, A.S. Gleiberman, S. Aygun-Sunar, J. Veith, C. Johnson, G.J. Haderski, P. Stanhope-Baker, S. Allamaneni, J. Skitzki, M. Zeng, E. Martsen, A. Medvedev, D. Scheblyakov, N.M. Artemicheva, D.Y. Logunov, A.L. Gintsburg, B.S. Naroditsky, S.S. Makarov, A.V. Gudkov, Central role of liver in anticancer and radioprotective activities of Toll-like receptor 5 agonist, Proceedings of the National Academy of Sciences of the United States of America 110(20) (2013) E1857-66.

[19] J. Kortmann, S.W. Brubaker, D.M. Monack, Cutting Edge: Inflammasome Activation in Primary Human Macrophages Is Dependent on Flagellin, Journal of immunology (Baltimore, Md. : 1950) 195(3) (2015) 815-9.

[20] J. Rolli, N. Loukili, S. Levrand, N. Rosenblatt-Velin, S. Rignault-Clerc, B. Waeber, F. Feihl, P. Pacher, L. Liaudet, Bacterial flagellin elicits widespread innate immune defense mechanisms, apoptotic signaling, and a sepsis-like systemic inflammatory response in mice, Critical care (London, England) 14(4) (2010) R160.

[21] R. Takamatsu, E. Takeshima, C. Ishikawa, K. Yamamoto, H. Teruya, K. Heuner, F. Higa, J. Fujita, N. Mori, Inhibition of Akt/GSK3beta signalling pathway by Legionella pneumophila is involved in induction of T-cell apoptosis, The Biochemical journal 427(1) (2010) 57-67.

[22] S. Okugawa, S. Yanagimoto, K. Tsukada, T. Kitazawa, K. Koike, S. Kimura, H. Nagase, K. Hirai, Y. Ota, Bacterial flagellin inhibits $\mathrm{T}$ cell receptor-mediated activation of $\mathrm{T}$ cells by inducing suppressor of cytokine signalling-1 (SOCS-1), Cellular microbiology 8(10) (2006) 1571-80.

[23] S. Thibault, M. Imbeault, M.R. Tardif, M.J. Tremblay, TLR5 stimulation is sufficient to trigger reactivation of latent $\mathrm{HIV}-1$ provirus in $\mathrm{T}$ lymphoid cells and activate virus gene expression in central memory CD4+ T cells, Virology 389(1-2) (2009) 20-5.

[24] Z. Ye, C.M. Lee, G.W. Sun, Y.H. Gan, Burkholderia pseudomallei infection of T cells leads to T-cell costimulation partially provided by flagellin, Infection and immunity 76(6) (2008) 2541-50.

[25] N. Sharma, A.S. Akhade, A. Qadri, Sphingosine-1-phosphate suppresses TLR-induced CXCL8 secretion from human T cells, Journal of leukocyte biology 93(4) (2013) 521-8.

[26] G. Koncz, A. Hancz, K. Chakrabandhu, P. Gogolak, K. Kerekes, E. Rajnavolgyi, A.O. Hueber, Vesicles released by activated $\mathrm{T}$ cells induce both Fas-mediated RIP-dependent apoptotic and Fas-independent nonapoptotic cell deaths, Journal of immunology (Baltimore, Md. : 1950) 189(6) (2012) 2815-23.

[27] I. Monleon, M.J. Martinez-Lorenzo, L. Monteagudo, P. Lasierra, M. Taules, M. Iturralde, A. Pineiro, L. Larrad, M.A. Alava, J. Naval, A. Anel, Differential secretion of Fas ligand- or APO2 ligand/TNF-related apoptosis-inducing ligand-carrying microvesicles during activation-induced death of human T cells, Journal of immunology (Baltimore, Md. : 1950) 167(12) (2001) 6736-44. 
[28] L. Zheng, G. Fisher, R.E. Miller, J. Peschon, D.H. Lynch, M.J. Lenardo, Induction of apoptosis in mature T cells by tumour necrosis factor, Nature 377(6547) (1995) 348-51.

[29] D. Spaner, K. Raju, B. Rabinovich, R.G. Miller, A role for perforin in activation-induced $\mathrm{T}$ cell death in vivo: increased expansion of allogeneic perforin-deficient $\mathrm{T}$ cells in SCID mice, Journal of immunology (Baltimore, Md. : 1950) 162(2) (1999) 1192-9.

[30] M.J. Martinez-Lorenzo, M.A. Alava, S. Gamen, K.J. Kim, A. Chuntharapai, A. Pineiro, J. Naval, A. Anel, Involvement of APO2 ligand/TRAIL in activation-induced death of Jurkat and human peripheral blood T cells, European journal of immunology 28(9) (1998) 2714-25.

[31] S. He, L. Wang, L. Miao, T. Wang, F. Du, L. Zhao, X. Wang, Receptor interacting protein kinase-3 determines cellular necrotic response to TNF-alpha, Cell 137(6) (2009) 1100-11.

[32] J. Zhao, S. Jitkaew, Z. Cai, S. Choksi, Q. Li, J. Luo, Z.-G. Liu, Mixed lineage kinase domain-like is a key receptor interacting protein 3 downstream component of TNF-induced necrosis, Proceedings of the National Academy of Sciences of the United States of America 109(14) (2012) 5322-5327.

[33] N. Holler, R. Zaru, O. Micheau, M. Thome, A. Attinger, S. Valitutti, J.L. Bodmer, P. Schneider, B. Seed, J. Tschopp, Fas triggers an alternative, caspase-8-independent cell death pathway using the kinase RIP as effector molecule, Nature immunology 1(6) (2000) 489-95.

[34] W.J. Kaiser, J.W. Upton, A.B. Long, D. Livingston-Rosanoff, L.P. Daley-Bauer, R. Hakem, T. Caspary, E.S. Mocarski, RIP3 mediates the embryonic lethality of caspase-8deficient mice, Nature 471(7338) (2013) 368-72.

[35] A. Oberst, C.P. Dillon, R. Weinlich, L.L. McCormick, P. Fitzgerald, C. Pop, R. Hakem, G.S. Salvesen, D.R. Green, Catalytic activity of the caspase-8-FLIP(L) complex inhibits RIPK3-dependent necrosis, Nature 471(7338) (2011) 363-7.

[36] H. Zhang, X. Zhou, T. McQuade, J. Li, F.K. Chan, J. Zhang, Functional complementation between FADD and RIP1 in embryos and lymphocytes, Nature 471(7338) (2012) 373-6.

[37] A. Degterev, J. Hitomi, M. Germscheid, I.L. Ch'en, O. Korkina, X. Teng, D. Abbott, G.D. Cuny, C. Yuan, G. Wagner, S.M. Hedrick, S.A. Gerber, A. Lugovskoy, J. Yuan, Identification of RIP1 kinase as a specific cellular target of necrostatins, Nat Chem Biol 4(5) (2008) 313-21.

[38] L. Sun, H. Wang, Z. Wang, S. He, S. Chen, D. Liao, L. Wang, J. Yan, W. Liu, X. Lei, X. Wang, Mixed Lineage Kinase Domain-like Protein Mediates Necrosis Signaling Downstream of RIP3 Kinase, Cell 148(1-2) (2012) 213-227.

[39] F. Steinhagen, T. Kinjo, C. Bode, D.M. Klinman, TLR-based immune adjuvants, Vaccine 29(17) (2011) 3341-55.

[40] A. Kaczmarek, P. Vandenabeele, D.V. Krysko, Necroptosis: the release of damageassociated molecular patterns and its physiological relevance, Immunity 38(2) (2013) 209-23.

[41] S. Tarahomjoo, Utilizing bacterial flagellins against infectious diseases and cancers, Antonie van Leeuwenhoek 105(2) (2014) 275-88.

[42] S.J. Conrad, M. El-Aswad, E. Kurban, D. Jeng, B.C. Tripp, C. Nutting, R. Eversole, C. Mackenzie, K. Essani, Oncolytic tanapoxvirus expressing FliC causes regression of human colorectal cancer xenografts in nude mice, Journal of experimental \& clinical cancer research : CR 34 (2015) 19.

[43] D. Geng, S. Kaczanowska, A. Tsai, K. Younger, A. Ochoa, A.P. Rapoport, S. OstrandRosenberg, E. Davila, TLR5 Ligand-Secreting T Cells Reshape the Tumor Microenvironment and Enhance Antitumor Activity, Cancer research 75(10) (2015) 1959-71.

[44] A.K. Panda, Induction of anti-tumor immunity and T-cell responses using nanodelivery systems engrafting TLR-5 ligand, Expert review of vaccines 10(2) (2011) 155-7. 
[45] C.T. Nguyen, S.H. Hong, J.I. Sin, H.V. Vu, K. Jeong, K.O. Cho, S. Uematsu, S. Akira, S.E. Lee, J.H. Rhee, Flagellin enhances tumor-specific CD8(+) T cell immune responses through TLR5 stimulation in a therapeutic cancer vaccine model, Vaccine 31(37) (2013) 3879-87.

[46] J.T. Bates, S. Uematsu, S. Akira, S.B. Mizel, Direct stimulation of tlr5+/+ CD11c+ cells is necessary for the adjuvant activity of flagellin, Journal of immunology (Baltimore, Md. : 1950) 182(12) (2009) 7539-47.

[47] S.E. Lee, S.H. Hong, V. Verma, Y.S. Lee, T.N. Duong, K. Jeong, S. Uthaman, Y.C. Sung, J.T. Lee, I.K. Park, J.J. Min, J.H. Rhee, Flagellin is a strong vaginal adjuvant of a therapeutic vaccine for genital cancer, Oncoimmunology 5(2) (2016) e1081328.

[48] P. Vandenabeele, W. Declercq, F. Van Herreweghe, T. Vanden Berghe, The role of the kinases RIP1 and RIP3 in TNF-induced necrosis, Sci Signal 3(115) (2010) re4. 


\section{Figure 1}

A

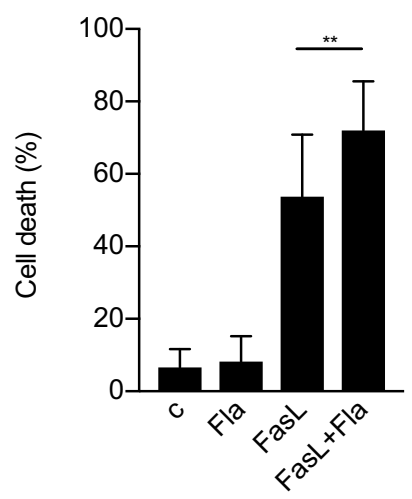

B

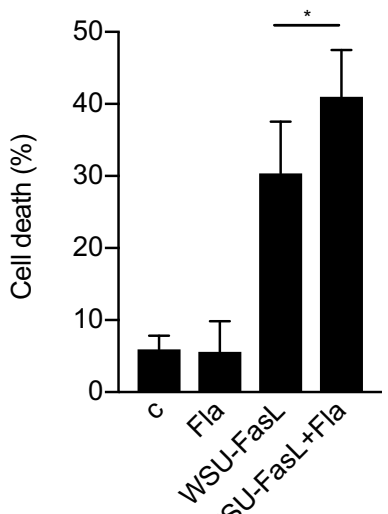

C

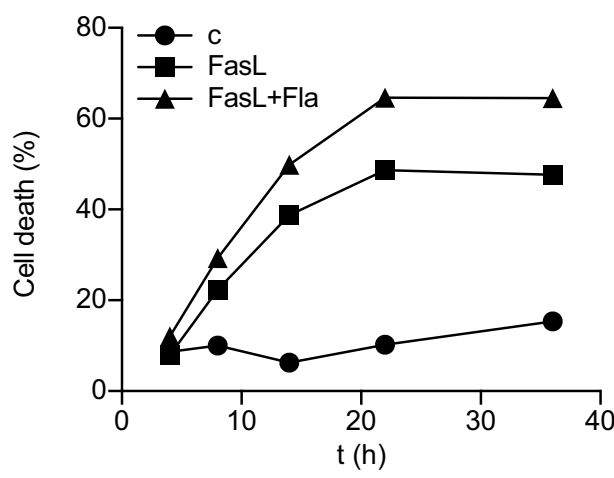


ns

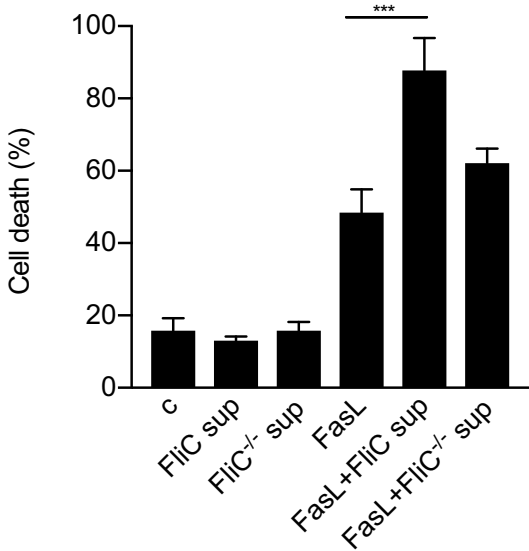


Figure 3

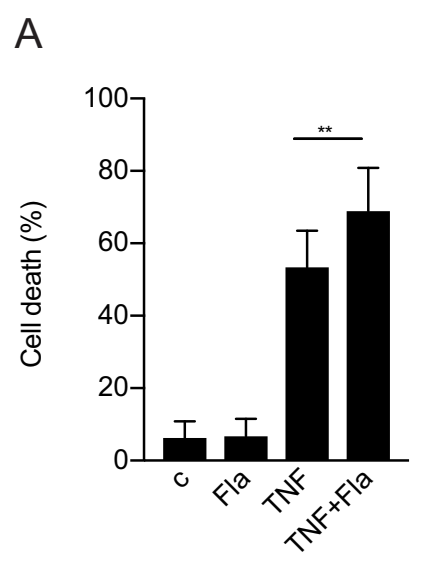

B

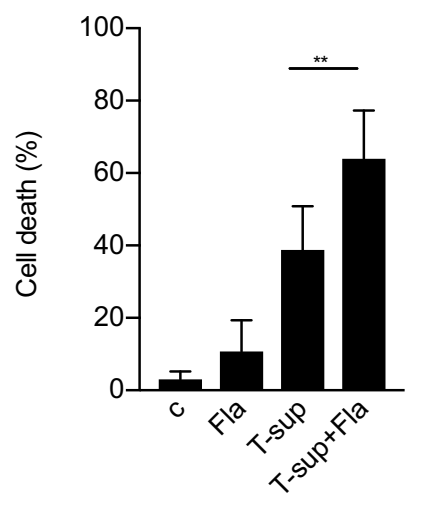

C

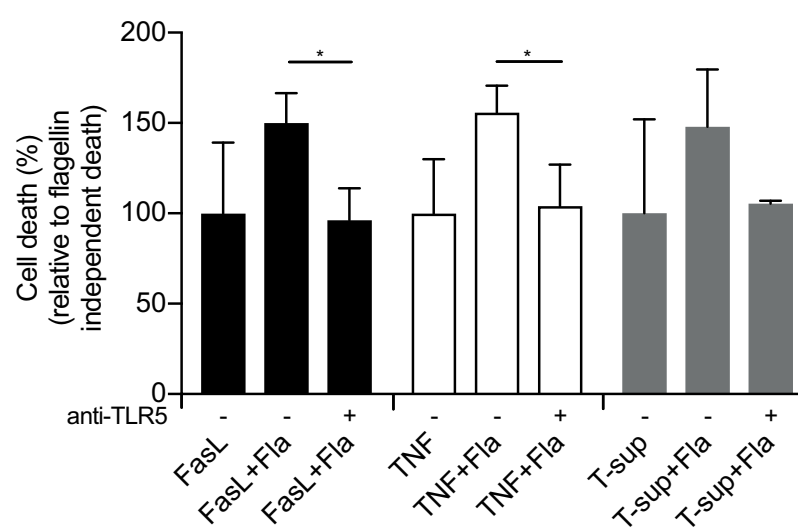




\section{Figure 4}

ns

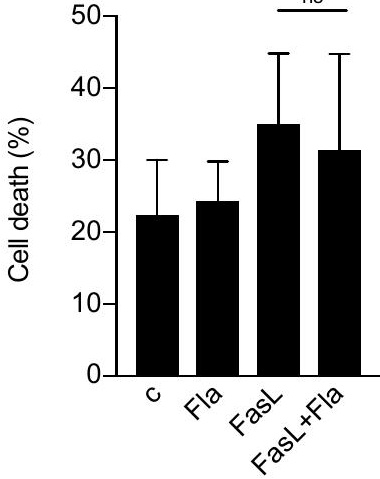




\section{Figure 5}

A

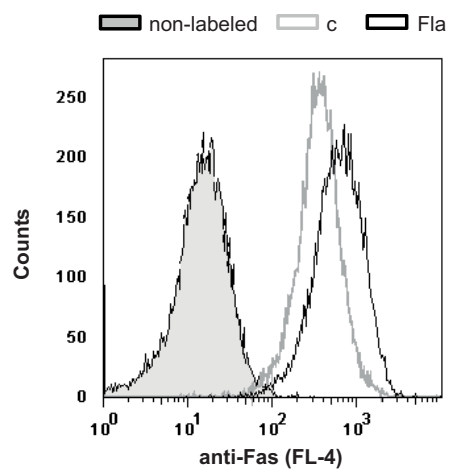

C

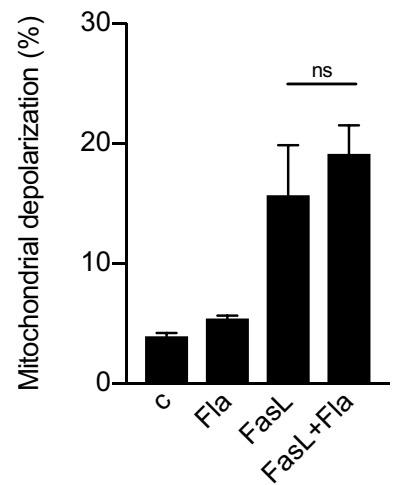

B

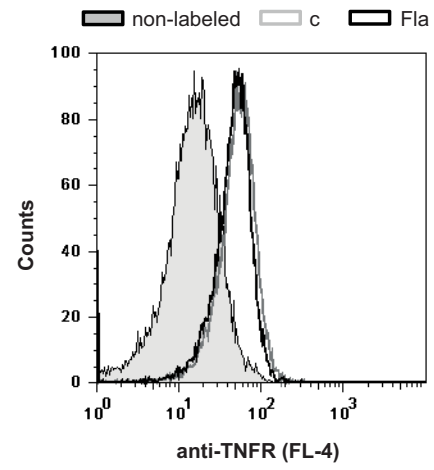

D

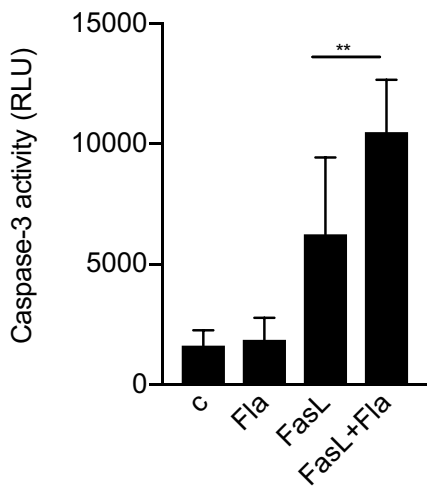


Figure 6

A

B
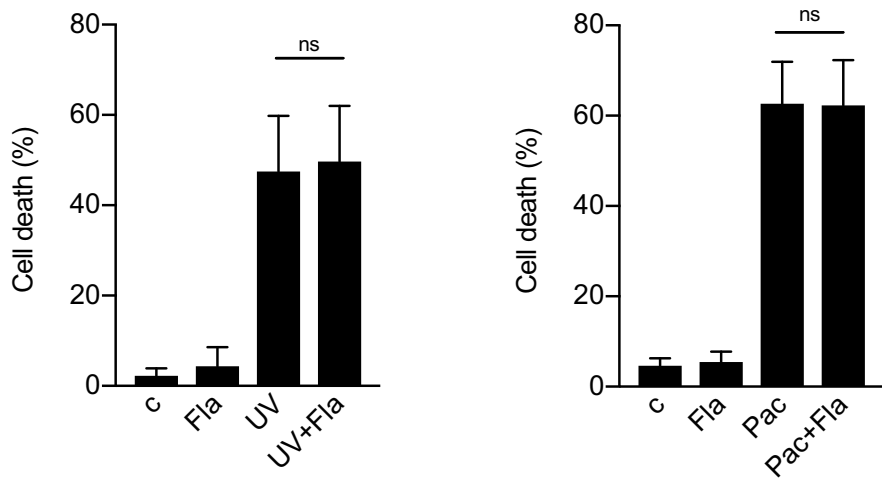
Figure 7

A

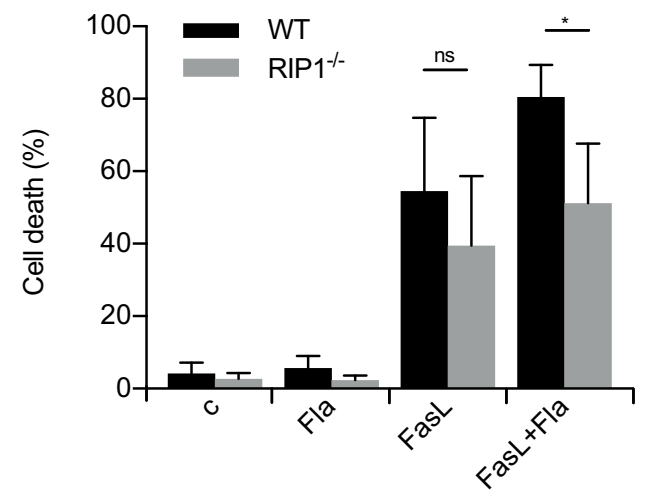

C

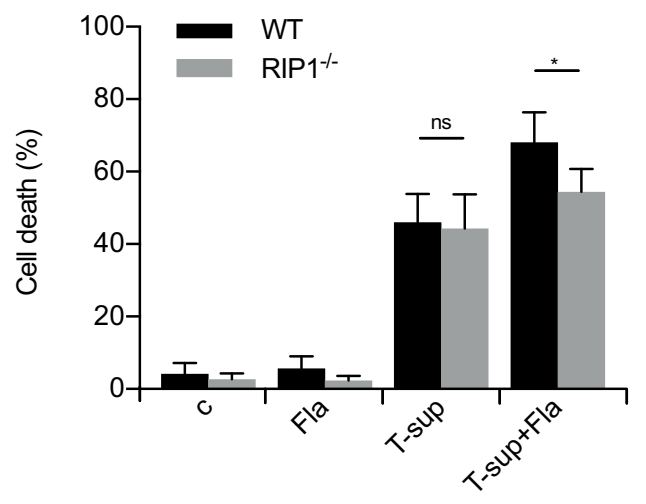

B

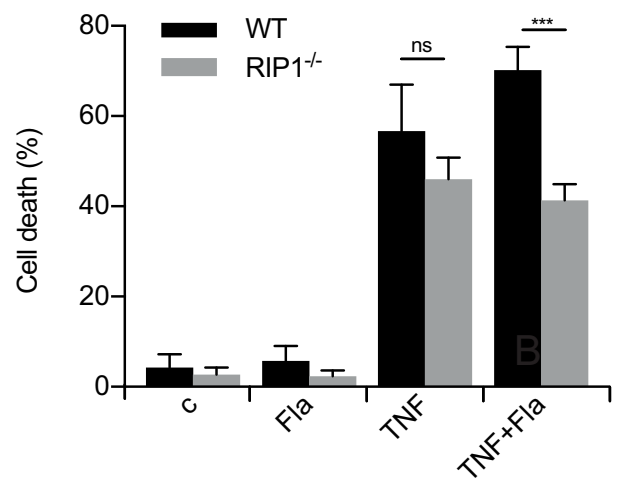

D

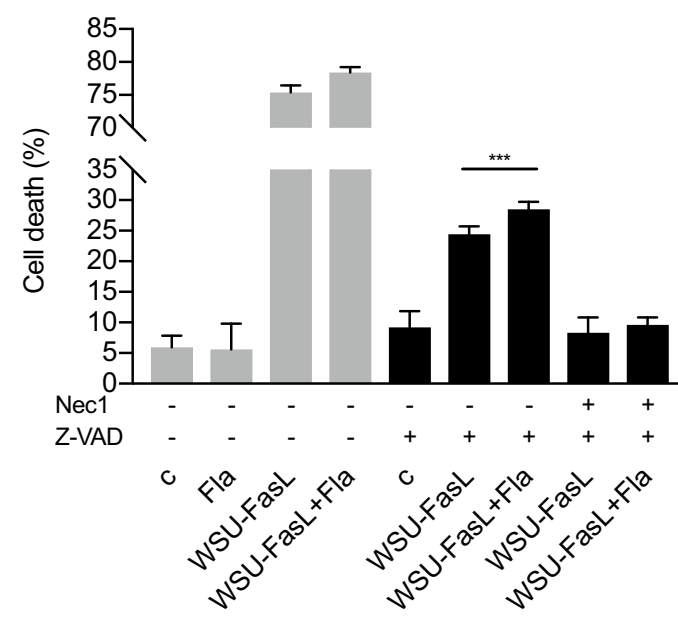


C

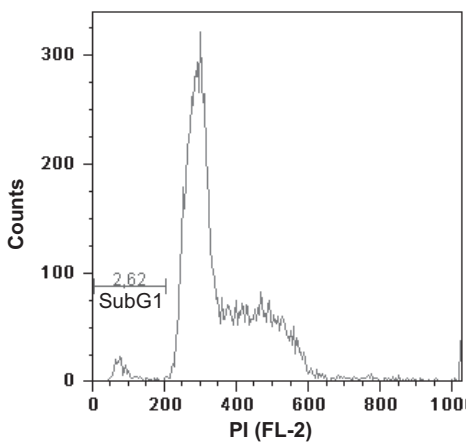

FasL

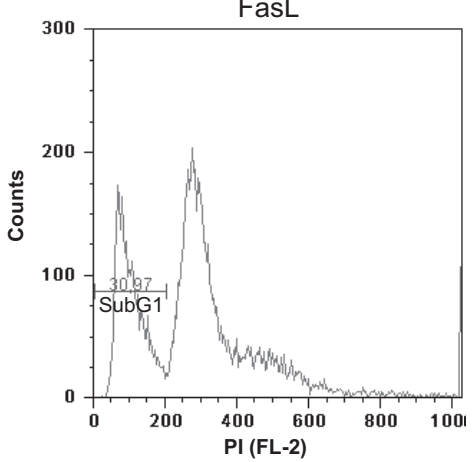

B

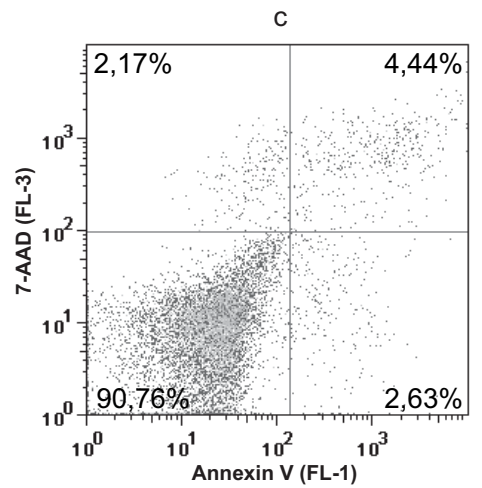

FasL

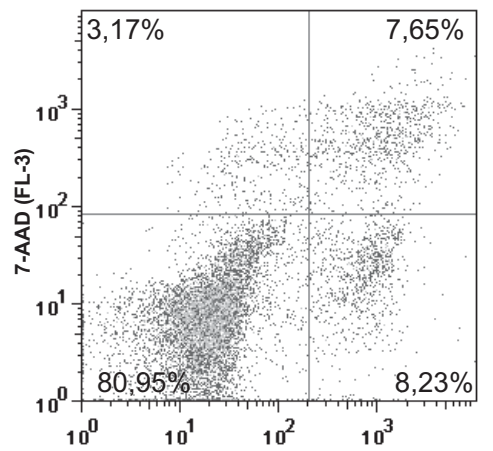

Fla

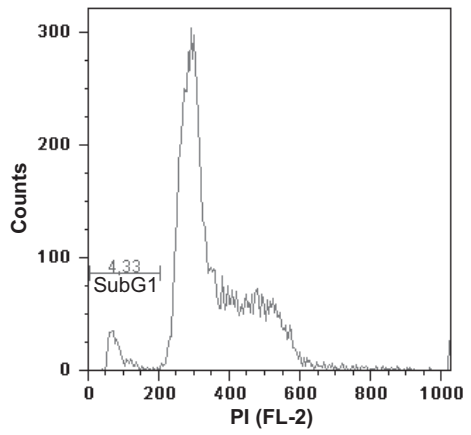

$\mathrm{FasL}+\mathrm{Fla}$

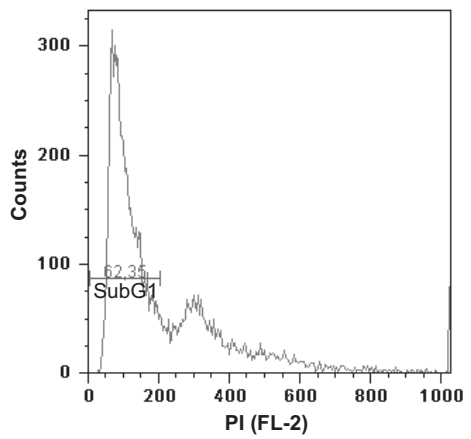

Fla

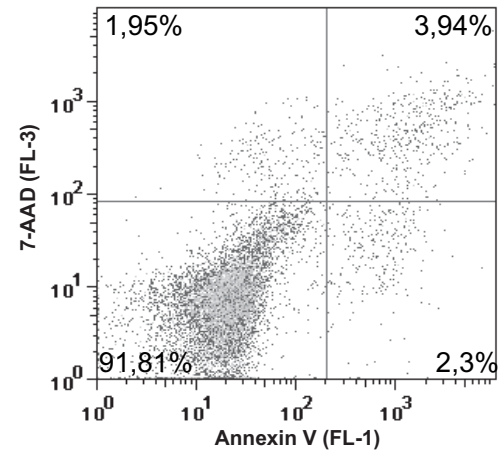

FasL+Fla

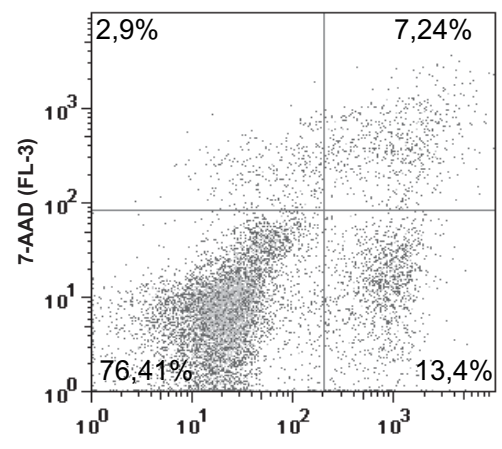
Annexin V (FL-1) Annexin V (FL-1) 